\title{
Calculation on Tensile Strength of Notched 2D Woven C/SiC Composite Laminates-Considering the Nonuniformity of Material

\author{
Hong-Bao GUO ${ }^{1, ~ a}$, Bo WANG ${ }^{1, b}$, Pu-Rong JIA ${ }^{1, c}$, Cheng-Peng YANG ${ }^{1, d}$
}

${ }^{1}$ School of Mechanics, Civil Engineering and Architecture, Northwestern Polytechnical University, Xi' An 710129, PR China.

aguohongbao1101@126.com, bb.wang@nwpu.edu.cn, cprjia@nwpu.edu.cn, dyang@mail.nwpu.edu.cn

Keywords: C/SiC Composites, Notched, Nonuniformity, Strength Prediction.

\begin{abstract}
The tensile strength of a 2D woven $\mathrm{C} / \mathrm{SiC}$ composite laminates notched with central hole was analyzed and calculated by finite element method. By considering the nonuniformity, material of open-hole specimen was divided into several parts with different density. Tensile properties of 2D woven $\mathrm{C} / \mathrm{SiC}$ composites with different density were gained through tests and calculations. Finally, a tensile strength computing model was built by taking the nonuniformity of material into account. The calculations go along well with the testing results.
\end{abstract}

\section{Introduction}

Woven continuous fiber-reinforced $\mathrm{SiC}$ matrix composites fabricated by chemical vapor infiltration route represent a crucial class of materials for a variety of high temperature air-breathing, space, and nuclear application [1]. Due to the characters of chemical vapor infiltration technique, there exist many pores within $2 \mathrm{D}$ woven $\mathrm{C} / \mathrm{SiC}$ composites, especially the larger-size pores between fiber bundles. These pores can make the density, elasticity [2,3] and strength [4] of local material decrease significantly.

Future composites components will process rather complex shapes to meet the needs of project design. During the preparation of composite components, complex shapes and large size will lead to more large-size pores within composites [5]. Meanwhile, there are serious stress concentrations occur around holes and notches of composites components, which are also caused by complex shapes [6]. The non-uniform distribution of pores causes density and properties of the material in composite components have nonuniform character. The local material which contains more pores has lower density and poorer mechanical properties. Combined with the effect of stress concentration, the nonuniformity of material can affect composite components' failure and bearing strength seriously. So investigation on tensile strength of notched $2 \mathrm{D}-\mathrm{C} / \mathrm{SiC}$ composite laminates must take material's nonuniformity into account.

Some work has been performed towards studying the stress redistribution mechanisms $[7,8]$ and failure modes [9] that operate in ceramic matrix composites subject to strain concentration, such as holes and notches. However, little has been done to study the effects of larger-size pores on tensile behavior of notched $2 \mathrm{D} \mathrm{C} / \mathrm{SiC}$ composite laminates. Also there is no tensile strength computing model, which is built by taking the distribution of pores between fiber bundles into account.

\section{Experimental Procedure}

\section{Specimen Preparation}

The applied 2D woven $\mathrm{C} / \mathrm{SiC}$ composite was produced by chemical vapor infiltration technique (CVI). Two groups of open-hole specimens both with an average density of $1.85 \mathrm{~g} / \mathrm{cm}^{3}$ were gained. The diameters of central holes are $4 \mathrm{~mm}$ and $6 \mathrm{~mm}$ separately, and donated as H4 and H6 specimens for short. The width of open-hole specimens both are $24 \mathrm{~mm}$. Three groups of smooth specimens were also prepared. Density values of these specimens are $1.85,2.0$ and $2.1 \mathrm{~g} / \mathrm{cm}^{3}$ separately. The 
smooth specimen has a dog-bone shape, and width is $10 \mathrm{~mm}$. Pictures of original specimens are shown in Fig.1.

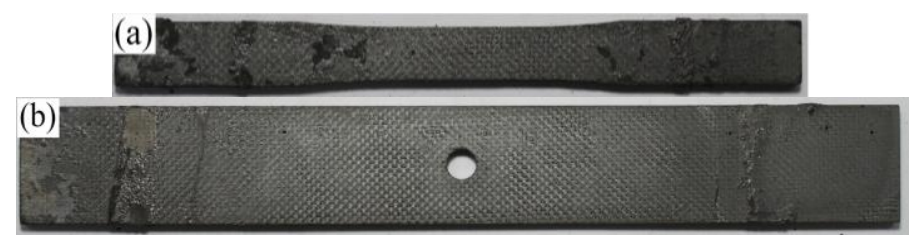

Fig.1 Pictures of Original Specimens (a) Smooth Specimen, (b) Open-hole Specimen.

\section{Tensile Test}

Tests were conducted on INSTRON 8801 machine with an uniform loading rate of $0.1 \mathrm{~mm} / \mathrm{min}$. During tests, strain data were obtained by sticking strain gauges on the surface of specimens. The locations of strain gauges are shown in Fig.2.
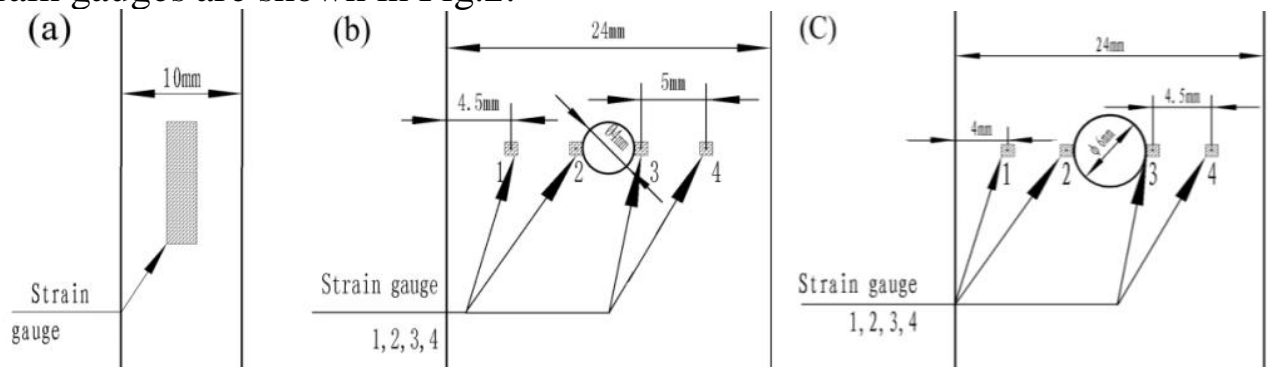

Fig.2 Locations of Strain Gauges Bonded on Specimen Surface (a) Smooth Specimen, (b)/(c) H4/H6 Specimen.

\section{Material Modeling}

\section{Pores Distribution}

The picture of the smallest net section of open-hole specimen is presented in Fig.3. There is a rectangle region at the center of section (enclosed by red line), where many large pores exist with an uniform distribution. However, few pores exist in region $\mathrm{B}$. The distance a is $0.4 \mathrm{~mm}$ and roughly equivalent to the thickness of two layers of $\mathrm{C}$ fiber woven clothes. The distance $\mathrm{b}$ is $0.8 \mathrm{~mm}$ and roughly equivalent to the size of one woven lattice. A high-density layer exists close to the surface of specimen. The above observation has a good agreement with the research results of Wei [10].

The material density in region $\mathrm{B}$ can be calculated as:

$$
\rho_{B}=\rho_{f} \times V_{f}+\rho_{m} \times V_{m}+\rho_{p} \times V_{p}
$$

where $\rho_{\mathrm{B}}$ is material density in region $\mathrm{B}$. Physical meanings and values of the other parameters in Eq. (1) are listed in Table 1. The calculated result of $\rho_{B}$ is $2.45 \mathrm{~g} / \mathrm{cm}^{3}$. By geometric calculation of open-hole specimen, volume fraction of region B is about $33 \%$. The average value of density for open-hole specimen is measured as $1.85 \mathrm{~g} / \mathrm{cm} 3$. So density of the material in region A is calculated as $1.56 \mathrm{~g} / \mathrm{cm}^{3}$.

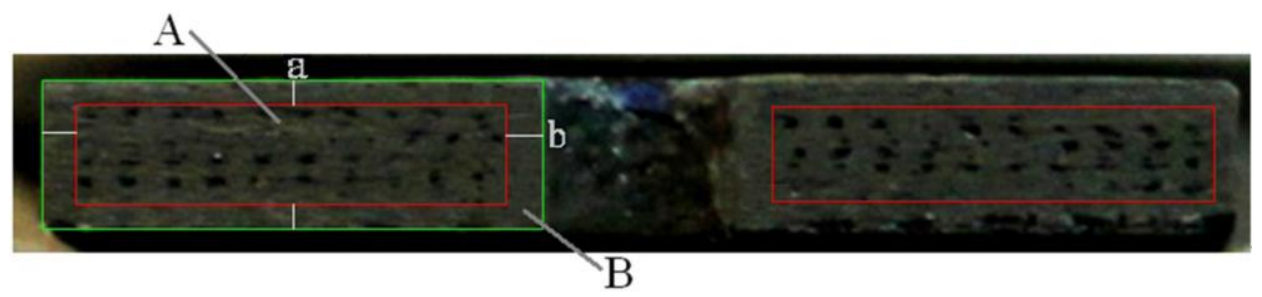

Fig.3 Picture of the Smallest Net Section of 2D-C/SiC Open-hole Specimen 
Tab.1 Density and Volume Fraction of Each Material Component in Region B

\begin{tabular}{cccc}
\hline & SiC Matrix & C Fiber & Pore \\
\hline density $\rho\left[\mathrm{g} \cdot \mathrm{cm}^{-3}\right]$ & 3.2 & 1.76 & 0 \\
Volume fraction $V[\%]$ & 55 & 40 & $5[2]$ \\
\hline
\end{tabular}

\section{Tensile Stress-strain Behaviors vs Density}

The typical tensile stress-strain curves of $2 \mathrm{D}$ woven $\mathrm{C} / \mathrm{SiC}$ composites with density of $1.85 \mathrm{~g} / \mathrm{cm}^{3}$ are showed in Fig.4. These curves are fitted well by a parabola [11] as:

$$
\sigma_{11}=0.865 \times\left(\sqrt{26 \times \varepsilon_{11}+16900}-130\right)
$$

where $\varepsilon_{11}$ and $\sigma_{11}$ are respectively tensile strain and applied tensile stress. Derivation and normalization were carried out for Eq. (2), and the result is:

$$
K=E_{\varepsilon 11} / E_{11}=1 / \sqrt{1.5385 \times 10^{-3} \times \varepsilon_{11}+1}
$$

where $E_{\varepsilon 11}$ and $E_{11}$ are tangent tensile modulus and the initial tensile modulus separately; $K$ is the descending coefficient of $E_{11}$ with $\varepsilon_{11}$. Relation curve of $\varepsilon_{11}$ and $K$ is given in Fig.5.

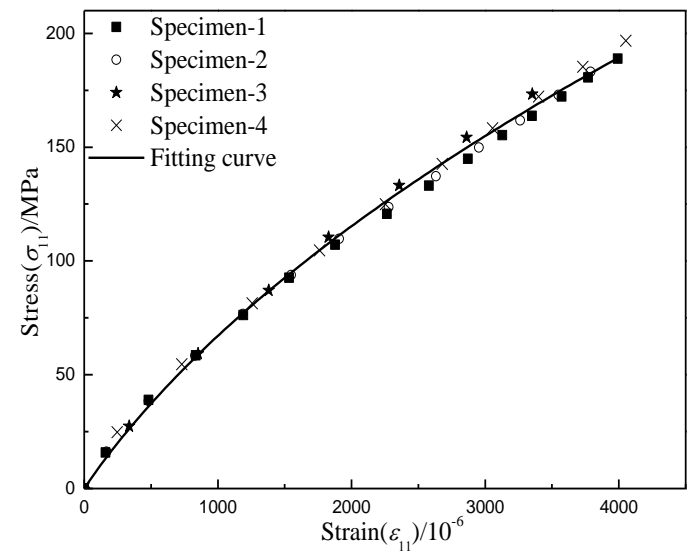

Fig.4 Tensile Stress-strain Curves of Smooth Specimens

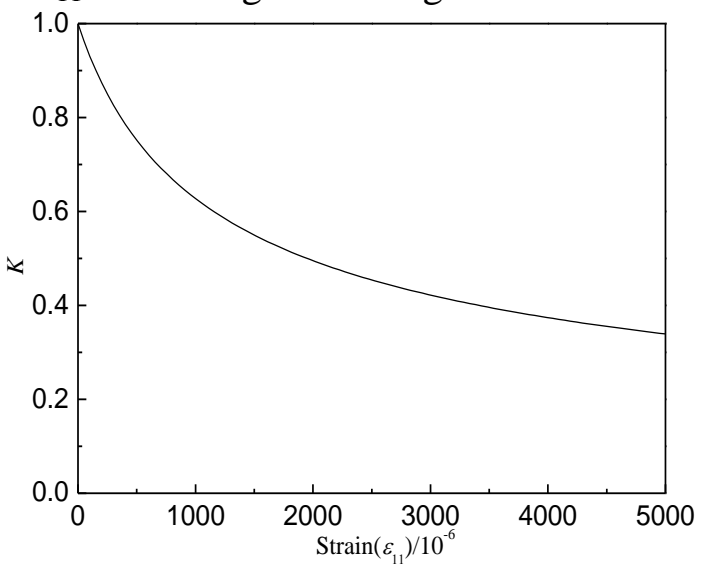

Fig.5 Curve of Descending Coefficient $\mathrm{K}$ and Tensile Strain $\varepsilon_{11}$

The relationship between $E_{11}$ and material density $\rho$ is linear [2]. By using test results of smooth specimens with different density, the linear relationship is fitted as:

$$
E_{11}=96.88 \times \rho-95.81
$$

The relationship between tensile strength and material density can be fitted as [4]:

$$
\sigma_{0}=\exp ^{\left(0.83+2.99 \times \rho-0.32 \times \rho^{2}\right)}
$$

where $\sigma_{0}$ is the tensile strength. The fitting curves and testing results are shown in Fig.6 together. The fitting results are in good agreement with testing results. 

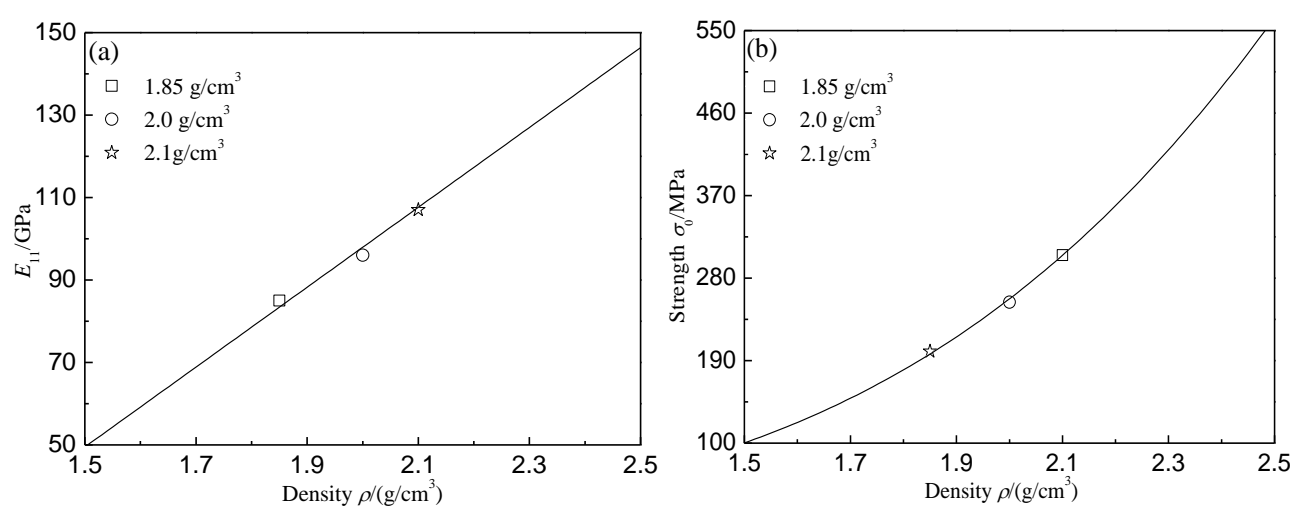

Fig.6 Testing Data and Fitting Curves of Elastic Tensile Modulus, Tensile Strength and Material Density of 2D-C/SiC Composites (a) E11 vs density $\rho$, (b) ${ }^{\sigma_{0}}$ vs density $\rho$

It is supposed that tensile stress-strain curves of material with different density have the same form. So tensile stress-strain curves of material with different density can be formulated as:

$$
\sigma_{11}=\left[E_{11}(\rho) / 100\right] \times\left[\sqrt{26 \times \varepsilon_{11}+16900}-130\right]
$$

Testing and fitting curves are shown in Fig.7 together, which show good agreement with each other.

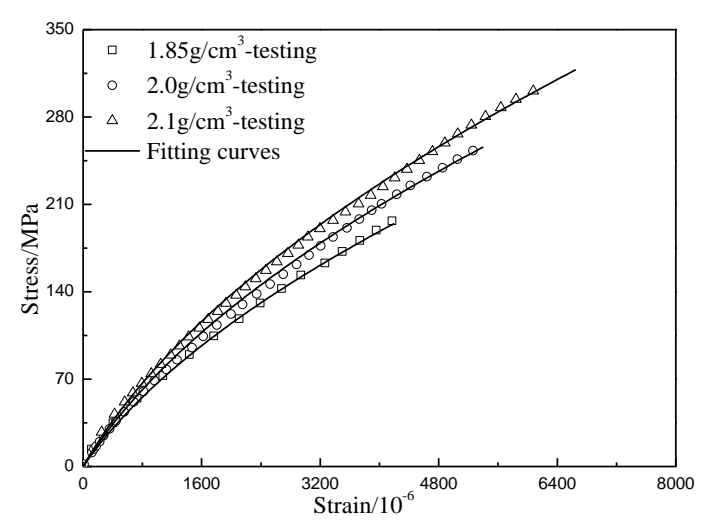

Fig.7 Tensile Stress-strain Curves of Material with Different Density

\section{Finite Element Model}

\section{Modeling}

Tensile strength computing models of open-hole specimens were built by Marc software. Eight-node, isoparametric, three-dimensional brick element with trilinear interpolation is adopted. To reduce calculating cost, one-eighth model was adopted. Based on the nonuniformity of material, the model was partitioned to gain region A and B separately. By considering the gradual change in density of local material, a transition region was also obtained. The size of transition layer is $0.2 \mathrm{~mm}$ in $\mathrm{Y}$ direction, and $0.1 \mathrm{~mm}$ in $\mathrm{Z}$ direction. The partition schematic of the model is shown in Fig.8. Matching material properties were assigned to the material in region A and B separately. The transition layer contains four small thin layers. Density of material in each layer from outside to inside is separately $2.27,2.09,1.91$ and $1.73 \mathrm{~g} / \mathrm{cm}^{3}$. And matching material properties were assigned to the material in each layer. Thus the variation in density of local material is smoother.

In model, material properties are described by 9 engineering elastic constants. Values of 9 engineering elastic constants of $\mathrm{M}_{2.0}$ were determined by tests or calculations, which are listed in Table 2. According to Eq. (4), $E_{11}$ of $\mathrm{M}_{1.56}$ and $\mathrm{M}_{2.45}$ are separately calculated as $52 \mathrm{GPa}$ and 
$142 \mathrm{GPa}$. It is assumed that values of another 5 engineering elastic constants $\left(E_{22}, E_{33}, G_{12}, G_{13}\right.$ and $G_{23}$ ) also change linearly with density of the material. In consideration of small influence on stress-strain calculation and consistency between values of engineering elastic constants, values of another three Poisson's ratio remain unchanged. Corresponding values of $\mathbf{M}_{1.56}$ and $\mathbf{M}_{2.45}$ are also listed in Table 3. Values of material in transition layer are also gained in this way.

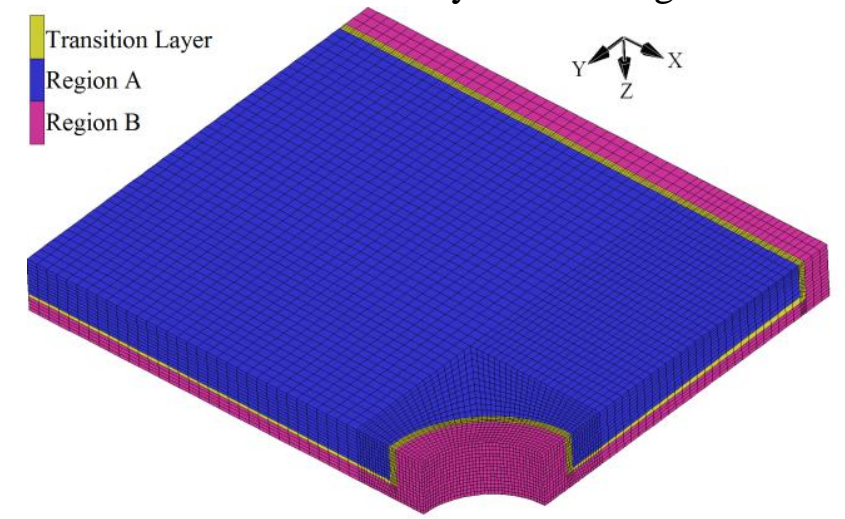

Fig.8 Partition Schematic of Open-hole Specimen in Model

Tab. 2 Values of 9 Engineering Elastic Constants of $\mathrm{M}_{2.0}, \mathrm{M}_{1.56}$ and $\mathrm{M}_{2.45}$

\begin{tabular}{cccccccccc}
\hline Material & $E_{11}[\mathrm{GPa}]$ & $E_{22}[\mathrm{GPa}]$ & $E_{33}[\mathrm{GPa}]$ & $G_{12}[\mathrm{GPa}]$ & $\begin{array}{c}G \\
{ }_{13}[\mathrm{GPa}]\end{array}$ & $\begin{array}{c}G \\
23\end{array}[\mathrm{GPa}]$ & $\mu_{12}$ & $\mu_{13}$ & $\mu_{23}$ \\
\hline $\mathrm{M}_{2.0}$ & 96 & 96 & 75.9 & 28.3 & 30.5 & 30.5 & 0.19 & 0.27 & 0.27 \\
\hline $\mathrm{M}_{1.56}$ & 142 & 142 & 112.2 & 41.8 & 45.1 & 45.1 & 0.19 & 0.27 & 0.27 \\
\hline $\mathrm{M}_{2.45}$ & 52 & 52 & 41.1 & 15.3 & 16.5 & 16.5 & 0.19 & 0.27 & 0.27 \\
\hline
\end{tabular}

In model, UPROGFAIL subroutine was used to describe the tensile stress-strain behavior of the material. Maximum strain was adopted as failure criterion to reflect the failure of the material. And failed material does not have bearing capacity anymore.

\section{Calculation and Discussion}

When applied loads on open-hole specimen both reach their maximums, data of $\varepsilon_{11}$ were extracted from models for analysis. As shown in Fig.9, the distribution curves of $\varepsilon_{11}$ on the smallest net section of open-hole specimens are gained. And the vertical axis represents the value of $\varepsilon_{11}$, the horizontal axis represents the distance away from hole-edge. There is obvious strain concentration around hole, which suggests that this part of material would fail first. Compared with $\mathrm{H} 4$ specimen, the variation gradient of $\varepsilon_{11}$ along the smallest net section of $\mathrm{H} 6$ specimen is larger. It illustrates that larger diameter-width ratio causes a larger variation gradient of $\varepsilon_{11}$ along the smallest net section.

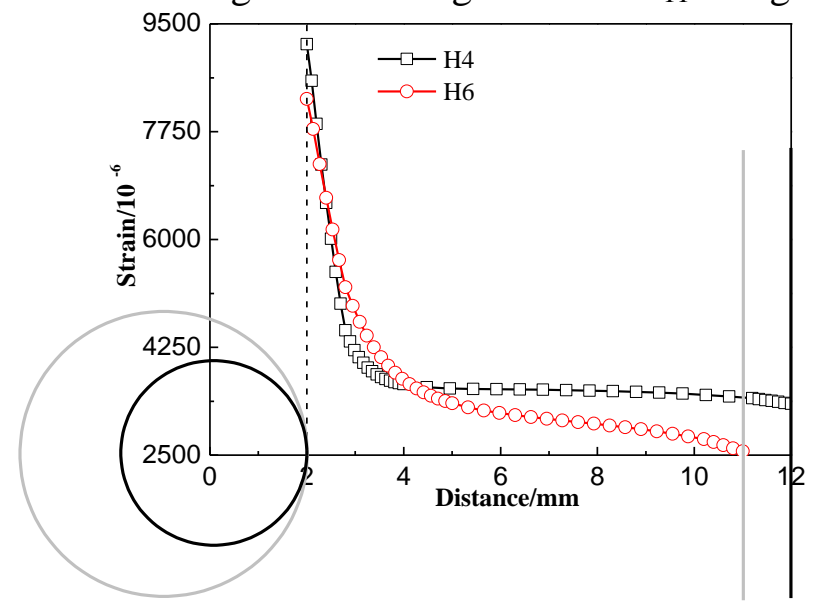

Fig.9 Distributions of $\varepsilon 11$ along the Smallest Net Section of Open-hole Specimens 
After failure just happens to local material of specimen, distribution maps of $\varepsilon_{11}$ are showed in Fig.10. For H4 specimen, location of first failed material is at the side of the central hole, which is caused by strain concentration around hole. For H6 specimen, location of first failed material is in region $\mathrm{A}$, on the smallest net section and near hole. The result is caused by strain concentration around hole and small fracture strain of $\mathrm{M}_{1.45}$ in region $\mathrm{A}$.
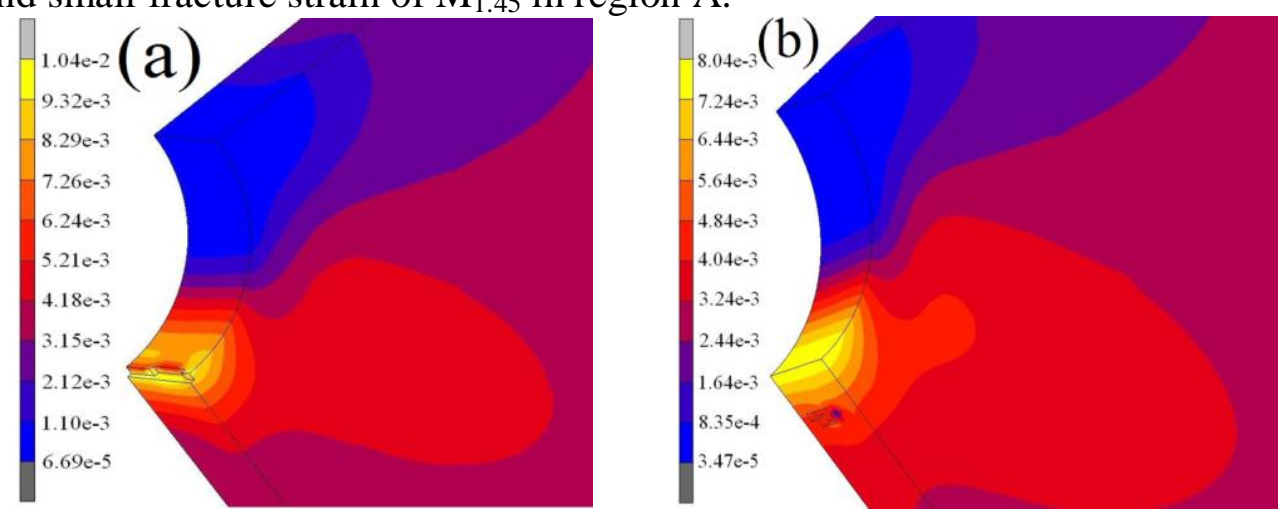

Fig.10 Locations of First Failed Material of Open-hole Specimens (a) H4 Specimen, (b) H6 Specimen
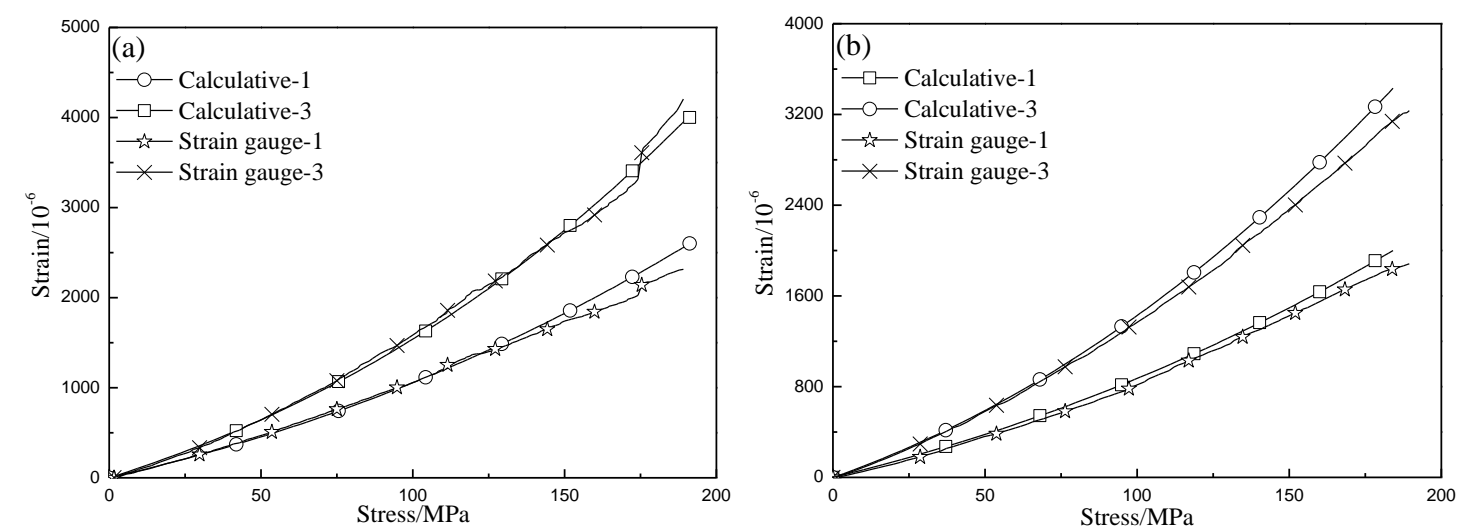

Fig.11 Stress-strain Data of Open-hole Specimens: Calculative Results vs Testing Results. (a) H4, (b) $\mathrm{H} 6$
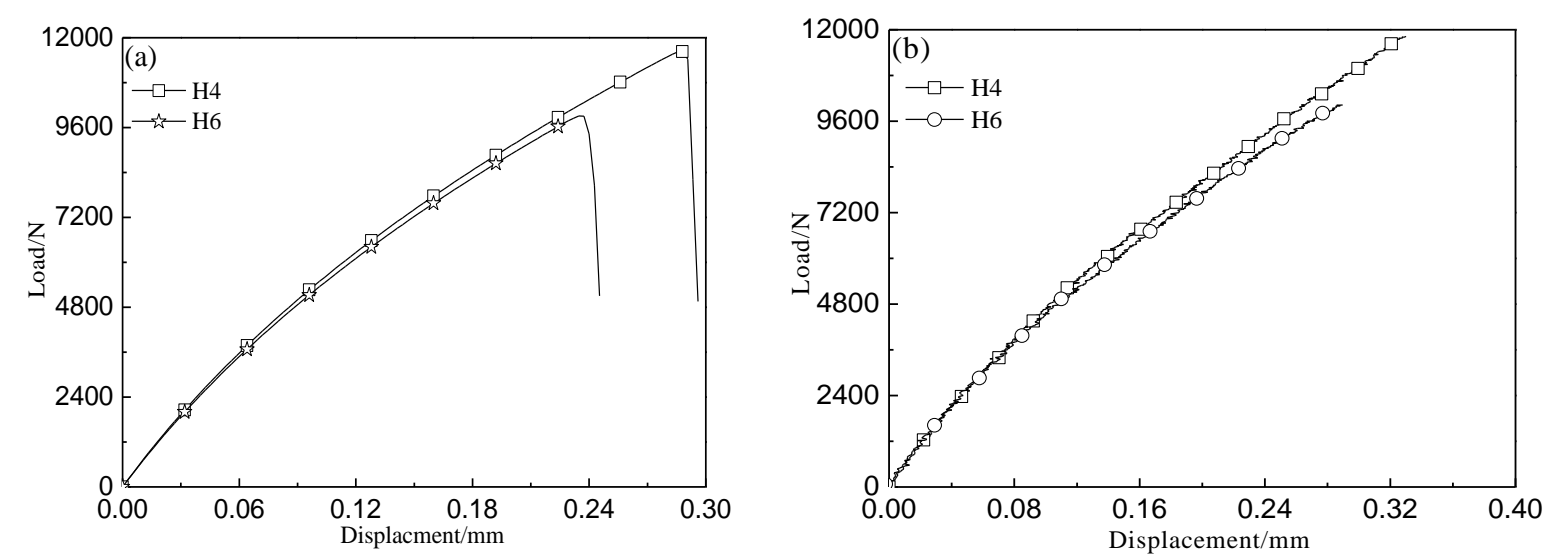

Fig.12 Curves of Applied Load and Displacement of Open-hole Specimens (a) Calculative Results, (b) Testing Results

On the smallest net section of open-hole specimens, curves of average applied stress and local tensile strain (gained from strain gauge 1,3) are shown in Fig.11. The matching calculative data were extracted from models and given in Fig.11 together. The calculative curves are in good 
consistent with testing curves. Calculative and testing curves of applied load and displacement are given in Fig.12 (a) and (b) separately. Shapes of these two groups of curves are similar. However, under the same applied load, testing displacement is a little larger than calculative result. It is because displacement in tests consists of two parts: extension of specimen and deformation of aluminum strengthening sheeting. The good agreement of calculation with testing results shows the rationality of tensile strength computing models.

\section{Prediction in Tensile Strength}

The effect of central hole's size on tensile strength of open-hole specimens was further investigated. As shown in Fig.13, when diameter of the central hole becomes $2 \mathrm{~mm}$, strain concentration around hole becomes higher and material around hole fail easily, which speeds up the damage evolution of open-hole specimen. However, the size of high strain concentration region becomes smaller, so there is not significant decrease in tensile strength. When the diameter increases $(2 \mathrm{~mm} \sim 4 \mathrm{~mm})$, strain concentration around hole becomes lower. And decrease in tensile strength is smaller. When hole's diameter increases to $4 \mathrm{~mm} \sim 8 \mathrm{~mm}$, variation gradient of $\varepsilon_{11}$ along the smallest net section of open-hole specimen becomes larger. It makes the damage evolution of material on the smallest net section becomes more asynchronous. So the decrease in tension strength of open-hole specimen becomes significant. When diameter of the central hole reaches $8 \sim 10 \mathrm{~mm}$, there is almost no change in tensile strength of open-hole specimen. Overall, because of the stress redistribution, 2D woven $\mathrm{C} / \mathrm{SiC}$ composites have small notch sensitivity. What's more, the high-density layer exists close to the surface of open-hole specimen is of great help to improve its notch sensitivity. However, if we assign properties of $\mathrm{M}_{1.85}$ to material in the whole model, and ignore material's nonuniformity, the predicted values of tensile strength are far less than testing values.

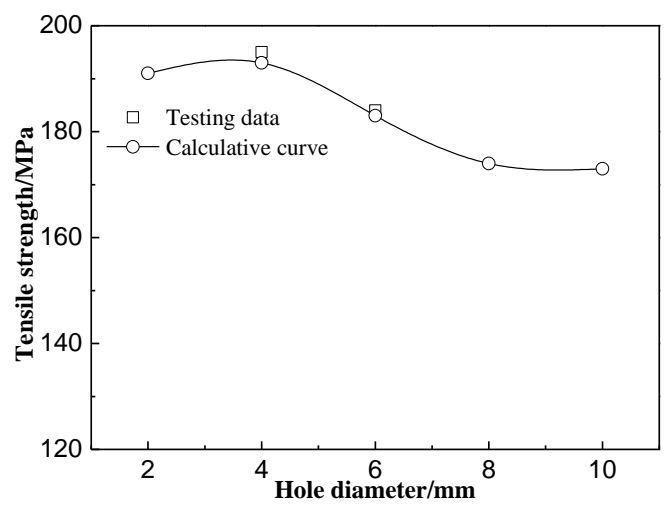

Fig.13 Relationship between Hole Diameter and Tensile Strength of Open-hole Specimens

\section{Conclusions}

According to the distribution of large-size pores between fiber bundles within $2 \mathrm{D} \mathrm{C} / \mathrm{SiC}$ composites, the nonuniformity of material of open-hole specimens was studied. There is an obvious variation in local material density of open-hole specimens. A high-density layer exists close to the surface of open-hole specimen, which is helpful to improve its notch sensitivity. A computing model was built by taking the above nonuniformity into account. By using uniaxial-tension data of 2D C/SiC composites with different density, tensile strength of open-hole specimen was predicted. The calculations go along well with testing results.

\section{References}

[1]R. Naslain: Comp. Sci. Technol. Vol. 64 (2004), p. 155.

[2]N.M. Gregory: Comp. Sci. Technol. Vol. 66 (2006), p. 2804. 
[3]P.W.M. Peters, E. Martin: Composites. Vol. 26 (1995), p. 108.

[4]C.P. Yang. Mechanical characterization and oxidation damage modeling of ceramic matrix composites, PhD thesis, Northwestern Polytechnical University, Xi'an, Shanxi, China, 2011, 51-60.

[5]Q.F. Zeng. Optimization design for C/SiC composites, PhD thesis, Northwestern Polytechnical University, Xi'an, Shanxi, China, 2004, 59-62.

[6]W.P. Keith and K.T. Kedward: Comp. Sci. Technol. Vol. 57 (1997), p.631.

[7]F.E. Heredia, S.M. Spearing and T.J. Mackin: J. Am. Ceram. Soc. Vol. 77 (1994), p. 2817.

[8]G.M. Genin, J.W. Hutchinson: J. Am. Ceram. Soc. Vol. 80 (1997), p.1245.

[9]J.C. McNulty, F.W. Zok and G.M. Genin: J. Am. Ceram. Soc. Vol. 82(1999), p. 1217.

[10]X. Wei, L.F. Cheng and L.T. Zhang: Computational Materials Science. Vol. 38(2006), p. 245.

[11]C.P. Yang, G.Q. Jiao and B. Wang: Chinese Journal of Theoretical and Applied Mechani. Vol. 43(2011), p. 330. 